"نشريه علوم زراعى ايران"

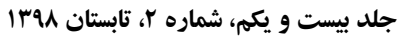

مقاله ئزوهشى

اثر مم آيارى و فاصله بوته روى رديف بر صفات مورفولوزيك و عملكرد دانه لاينهاى

اميدبخش سوركوم دانهاى (Sorghum bicolor L. Moench)

Effect of deficit irrigation and within row spacing on morphological traits and

grain yield of grain sorghum (Sorghum bicolor L. Moench) promising lines

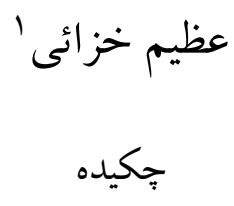

خزائى، ع.، لهو ا. اثركم آبيارى و فاصله بوته روى رديف بر صفات مورفولوزيكك و عملكرد دانه لاينهـاى اميدبخش سورگوم دانهاى (Sorghum bicolor L. Moench). نشريه علوم زراعى ايران. آم(r): 1+ 1-7ح.

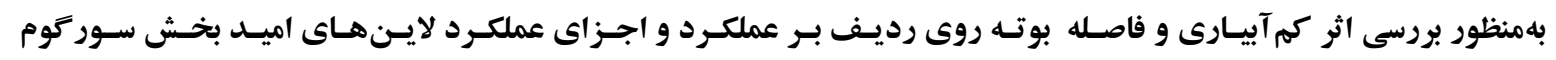

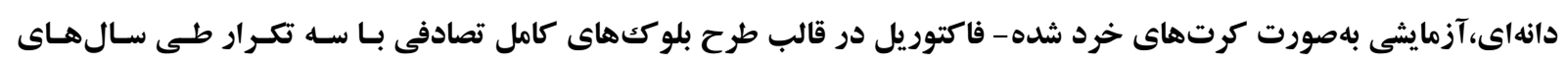

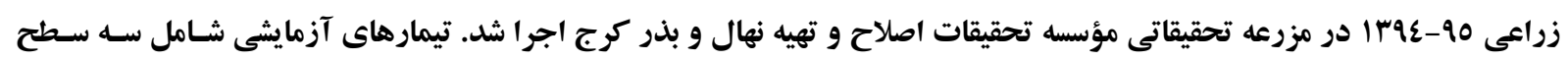

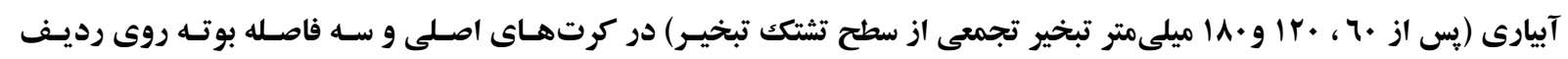

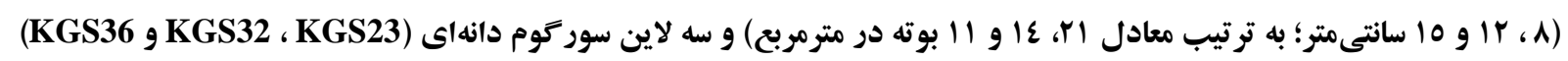

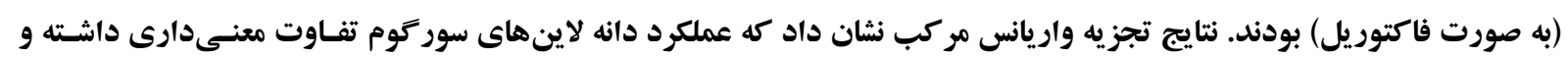

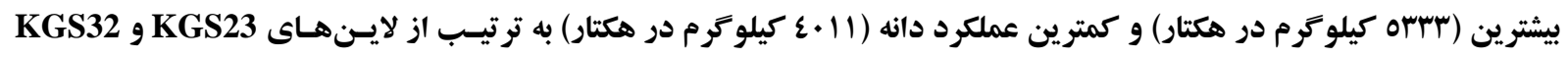

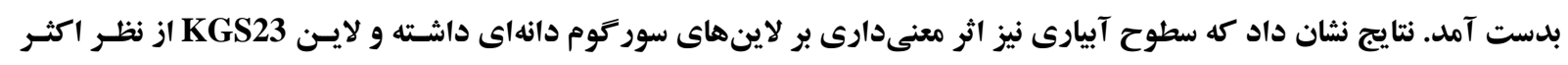

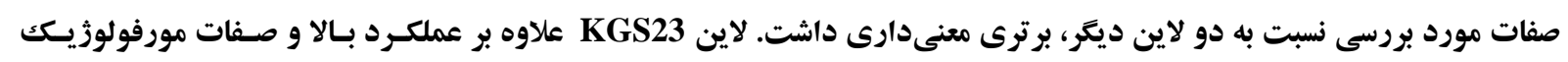

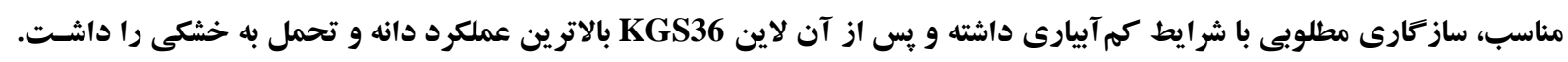

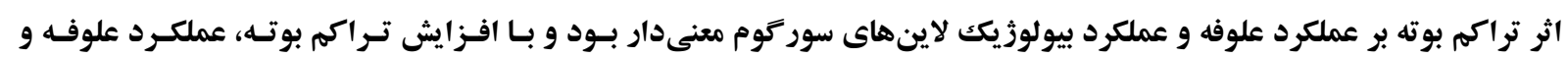

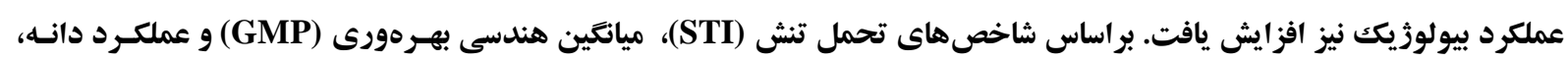
سور كوم لاين اميدبخش KGS23 كه در كليه سطوح آبيارى عملكرد دانه بالاترى داشت، بهعنوان لاين متحمل به شرايط كم آبيارى با عملكرد بالا شناسايى شد.

وازههاى كليدى: آبيارى محدود، سور كوم دانهاى، شاخص تحمل تنش و عملكرد علوفه.

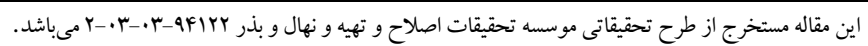

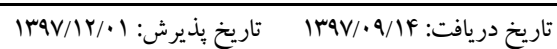

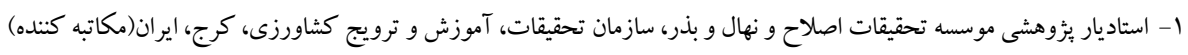

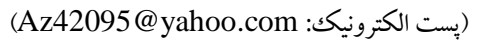


و فواصـل آبيـارى كمتــر و يـا بيشـتر، بـهـ علـت عــدم

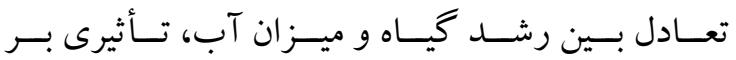
عملكرد نخواهد داشـت. بـهـ گَزارش اونكـن و ونـــت (Onken and Wendet, 1992)

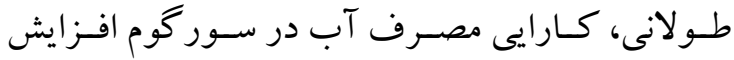
مى يابد. امجـدعلى و همكـاران (Amjad Ali et al., 2009) بـا

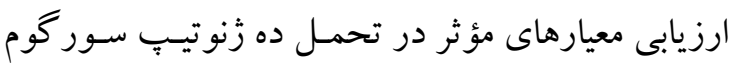

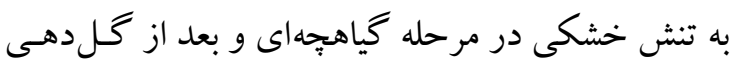

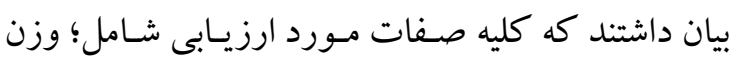

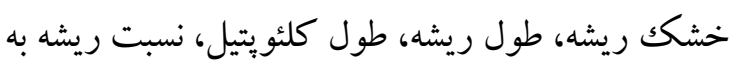

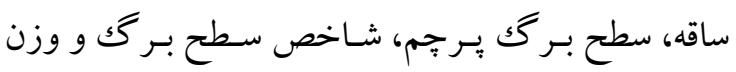

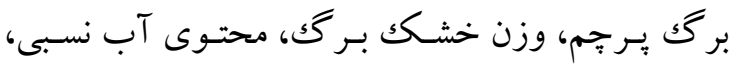

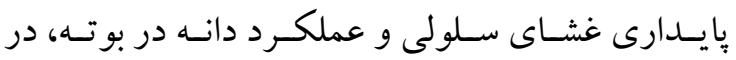

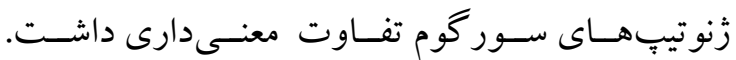

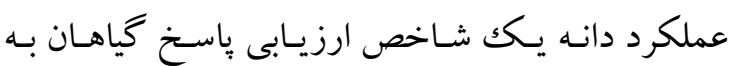

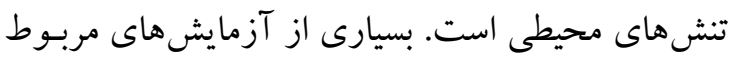

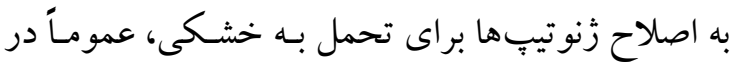

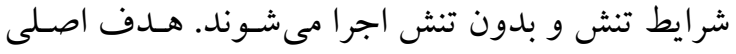

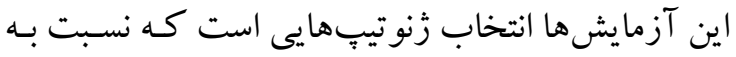
هر دو شر ايط ساز گار باشند (Fernandez, 1992). تعيسين

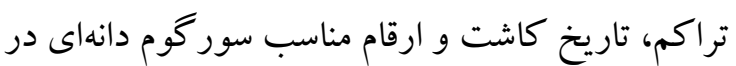

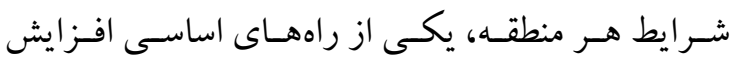

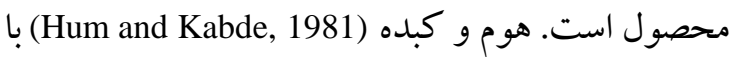

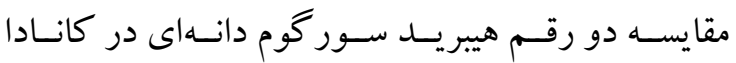

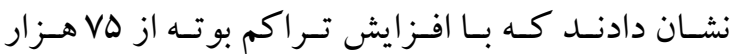

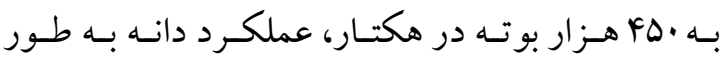

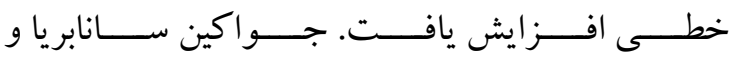
همكـــاران (Joaquin Sanabria et al., 1995) كَزارش كردنـد كـه در هنخَام خشـكى بـالاى محـيط،

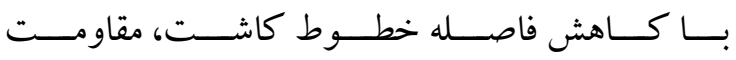

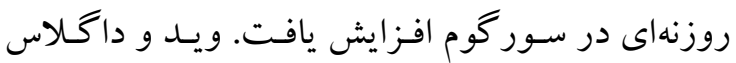
(Wade and Douglas, 1990)

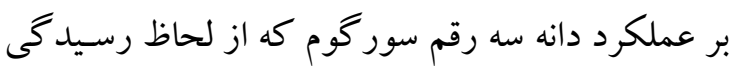

\section{مقدمه}

عملكرد دانه يكى از مهم ترين صفات براى گـزينش

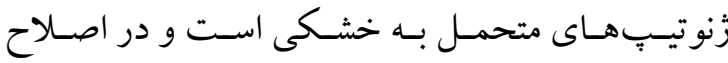

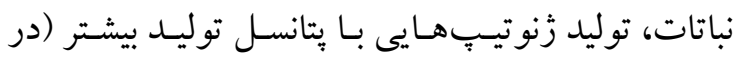

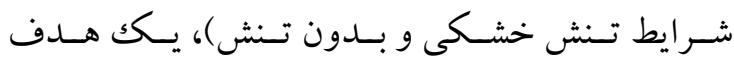
محسوب مى شود، بنابر اين كَزينش بـراى سـاير صـفات تحمل خشكى بدون در نظر كرفتن عملكرد دانه، نتيجـه جنــدانى نخواهـد داشـت (Schaffert et al., 2011). عملكرد مطلوب سـور گوم در منـاطق خشـك، افقهـاى تازهاى در توليد اين گياه كشوده است. با توجـه بـه نيـاز روزافـزون جامعسه جهـت تــأمين بـروتئين مـورد نيـاز و خشك بـودن منـاطق وسـيعى از ايسران و سـاز گار بـودن سور گوم به شرايط خشكى و تحقيقـات انـدكى كـه در خصوص جنبه هاى بـهزراعى سـور گوم در كشـور انجـام كر فته، خلاء تحقيقاتى در اين زمينه احساس مىشود. تراكم بوته از طريق اثر بر اجزاى عملكرد، عملكرد

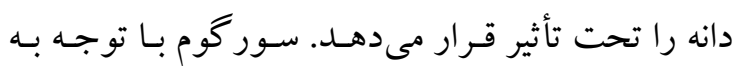
خصوصيات مورفولوزيكى و فيزيولـوزيكى منحصـر بــ فردى كه دارد، بهعنوان شاخص گياهان زراعى متحمـل به خشكى معرفى شده و نسبت به سـاير گياهـان زراعى

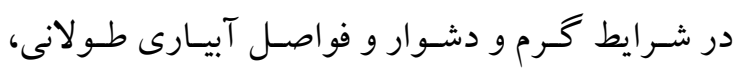
متحمل تر بوده و نياز آبى كمترى دارد (Ehdaei, 2004). سور گوم دانهاى بهعنو ان غذاى اصلى بر اى ميليونها نفـر

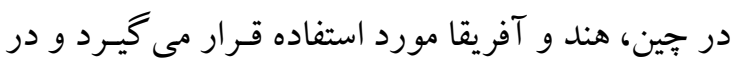
ساير نقاط جهان نيز براى تغذيسه دامهـا و طيسور كـاربرد

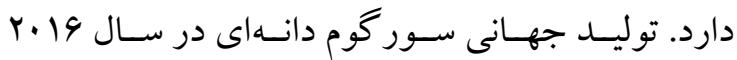
حدود • ^ميليون تن بوده است كه به ترتيـب اهميـت در بين غـلات، يسس از كنـدم، بـرنج، ذرت و جـو در رتبـه يسنجم قـرار مى كيـــد (FAO, 2016). جــاترجى و داس (Chatterjee and Das, 1989) بـه حسدود يـنج تـا هفـت هـزار متـر مكعـب در هكتـار

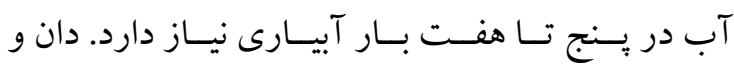
همكاران (Done et al., 1984) گز ارش كردنـد كـه دور آبيارى مناسب براى سورگوم دانهاى با تا ل1 روز بوده 


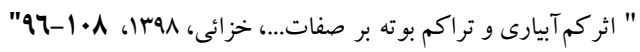

درجه و ه9 دقيقه شمالى و عرض جغرافيايى •ه درجه و VD دقيقه شرقى انجام شد. سـال قبـل از آزمـايش، زمسين آيش بود. بافت خاكك مزرعه آزمايشى رسسى - شـنى بـا اسيديته V/D و هدايت الكتريكى VD/ · دسـىزيمسنس بـر متر بود. خاكك مزرعه آزمايشى داراى 9 درصد كربنات

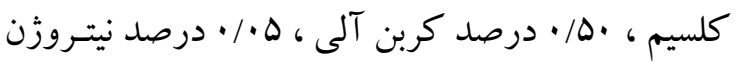

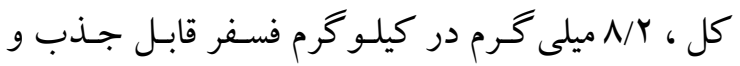

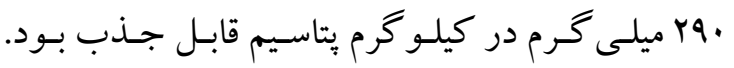

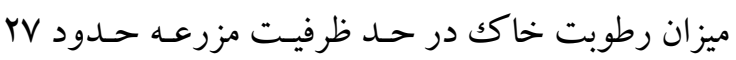
درصد وزنى و جرم مخصوص ظاهرى خاكك وس/ آكرم بر سانتى متر مكعب بود. آزمايش بهصورت كرتهـاى خرد شده - فاكتوريل در قالب طـرح بلو ككهـاى كامـل

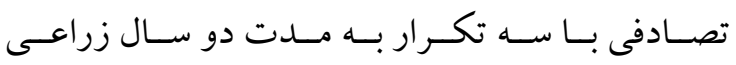

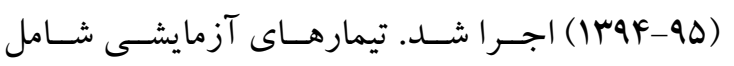

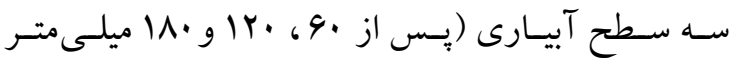

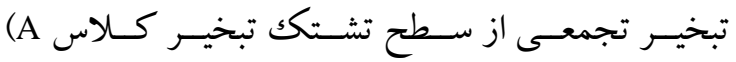
در كرتهـاى اصسلى و ســه فاصـله بو تـه روى رديسف

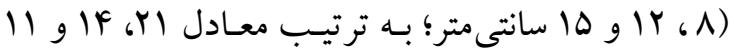

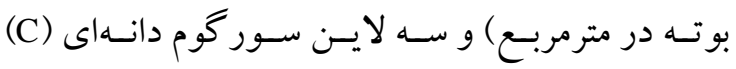
(بGS36 و KGS32 ، KGS23) (بهورت فاكتوريـل؛ (KG) در كرتهــاى فرعسى) بودنــد. ايسن لايـنـهـا حاصـل

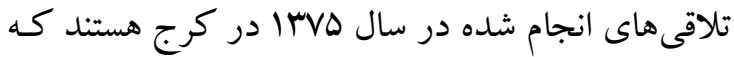
بـه روش شـجرهاى بـه مـــت هفـت سـال خالص سـازى شدهاند. KGS23=21 -2/1375 ، KGS32 - 4/1375 1/1375 - 15GS36=15. هر كرت آزمايشى شامل جهار خط كاشت به طول ينج متر با فاصله •9 سـانتىمتر بـود. ها كيلـو گرم در هكتـار فسـفر (از منبـع كـود فسـفات آمونيوم) و •ه كيلو كرم در هكتار نيتروزن (از منبع كود اوره) در زمان كاشت و •ه كيلو گرم در هكتار نيتروزن بهصورت سركك در مرحله ^- 9 بركى، بر اسـاس نتـايج آزمون خاكك مصرف شدند. صفات گياهى اندازه گيرى شده شامل؛ ارتفاع بوته، طـول خوشـه، قطر سـاقه، وزن خوشه، عملكرد علوفه، عملكـرد بيولوزيـك، وزن هـز ار

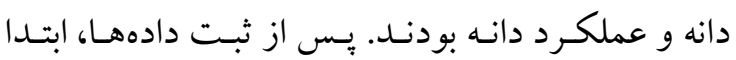

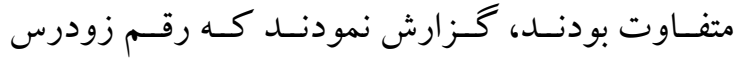
جهت توليد حداكثر عملكرد، نسبت به ارقام ديررس، به

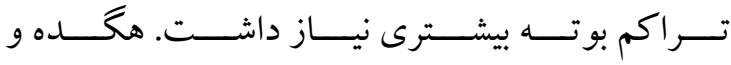
همكـاران (Hegde et al., 1976) در سـه آزمـايش روى دو رقـم هيبريســ سـور گوم دانسهاى نشــان دادنـــ كـه در دو آزمايش به ترتيب بـا افز ايش تـراكم از AV بـه وبه و

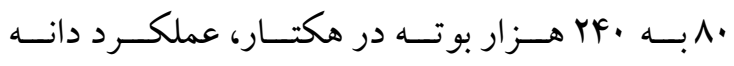
افـز ايش معنسى دارى نداشــت، امـا در يـكك آزمـايش بـا

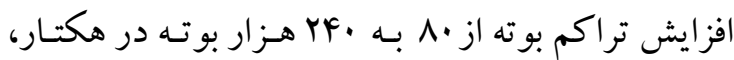

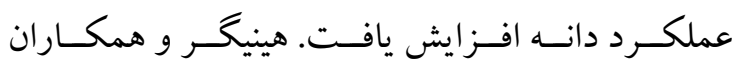
(Heiniger et al., 1993) قسمت هاى مختلف خوشه و عوامل مؤثر بر اين تنوع در دو رقم سور گوم در هفت تر كيب مختلف تراكم بوتسه و

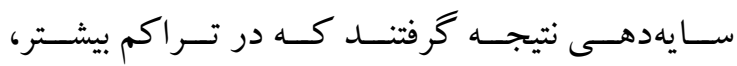

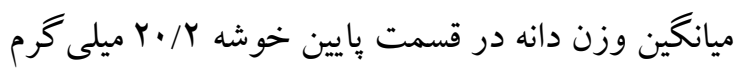

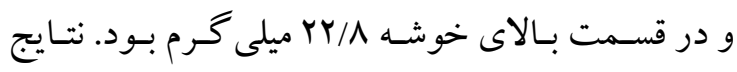

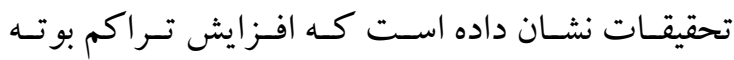
باعث كاهش دانه در خوشه مىشود. جلالسى و بحرانى F/V با مقايسه جهـار تـراكم (Jalali and Bahrani, 2001)

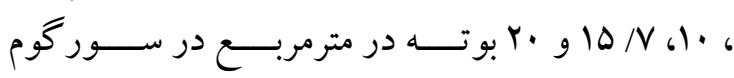

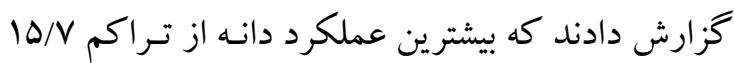
بوتسه در متـر مربـع حاصـل شـد. روسـولم و همكـاران

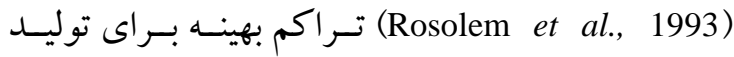
حداكثر دانه در سـوركوم دانسهاى را ساب هـزار بوتـه در هكتار گز ارش كردند. به گَز ارش كامـاس و همكـاران افزايش تـراكم بوتسه تـأثيرى بـر (Gamase et al., 1986) عملكرد دانه سوركوم نداشت. اين يثوهش به منظور مقايسـه اثـر تيمارهـاى تـراكم

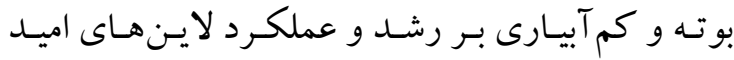
بخش سور كوم دانهاى اجرا شد.

\section{مواد و روشها}

اين آزمايش در مزرعه تحقيقاتى مؤسسـه تحقيقـات

اصلاح و تهيه نهال و بذر در كرج با طول جغر افيايى هـ 
شاخص هاى كمى تحمل و حساسيت بـه تـنش بـه شـرح روابط زير محاسبه شده و شاخص هاى مناسب تحمل بـه خشكى و زنوتيبٍ هاى متحمـل شناسـايى شـدند. تجزيـه واريانس، مقايسه ميانگين ها و همبستخى ها با استفاده از

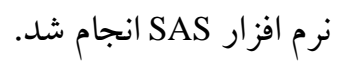

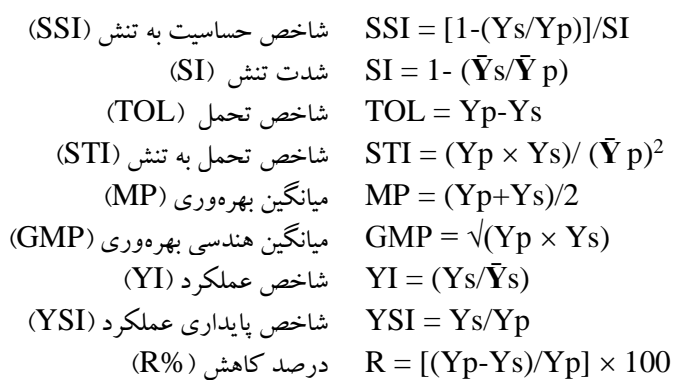

مفروضـات تجزيسه واريــانس آزمــون شــده و يسـس از اطمينان از برقرارى مفروضات، تجزيه واريـانس دادههـا به صورت مر كب انجام شد. با استفاده از عملكرد ارقـام

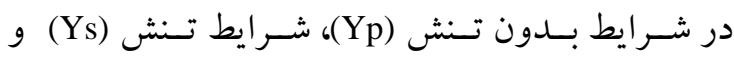

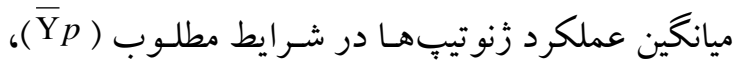

كاهش بيدا كرد. نتـايج تجزيـه واريـانس نشـان داد كـهـ

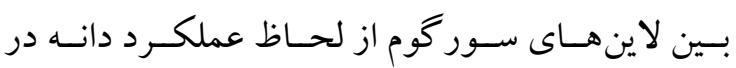

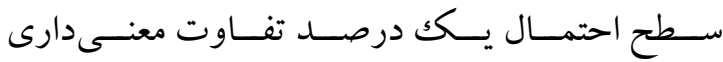

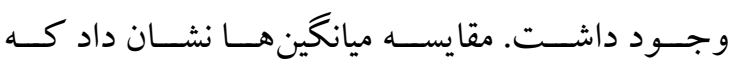
لاين KGS23 و لاين KGS36 به ترتيب با عملكرد دانسه

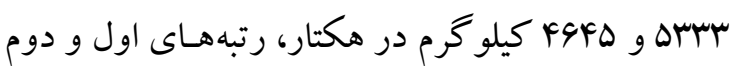

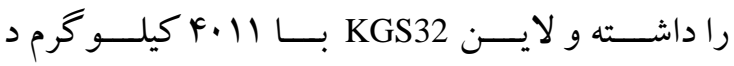
ر هكتار داراى يايينترين عملكرد دانه بـود (جـدول (). بـه نظـر مسىرســ كـه در تيمـار بــدون تسنش، مصسرف

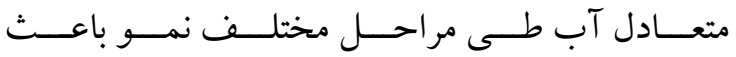
بهبود عملكرد دانه لاين هـاى سـور گوم شـد. تسـريع در

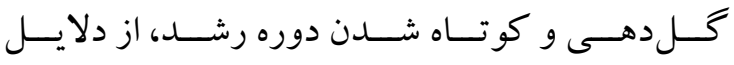
كاهش عملكـرد محسـوب مى شـوند. فـرارى و فرنانــز (Ferrari and Fernandez, 1986) تنش خشكى در آفتـابگر دان سـطح بر كَهـا بـه سـرعت كاهش يافته و تأثير منفى بر عملكرد دانسه داشـت. زمـان بـروز تسنش خشـكى نيـز در ميـزان خسـارت وارده بـر

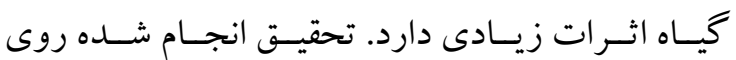

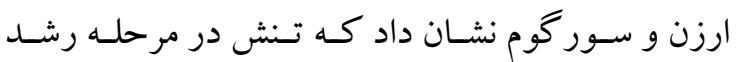

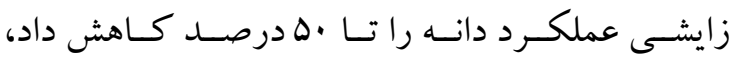
اما وقوع تنش در مرحله رشد رويشى باعـث كـاهش ها

\begin{tabular}{|c|c|}
\hline (Fisher and Maurer, 1978 ) & 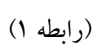 \\
\hline (Fisher and Maurer, 1978 ) & (رابطه r) (r) (ر) \\
\hline (Rosielle and Hambline, 1981) & (رابطه س) \\
\hline (Fernandez, 1992) & 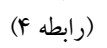 \\
\hline (Rosielle and Hambline, 1981) & (رابطه ها) \\
\hline (Fernandez, 1992) & 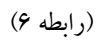 \\
\hline (Gavazzi et al., 1997 ) & (رابطه V) (رابط) \\
\hline (Bouslama and Schapaugh, 1984 ) & 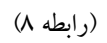 \\
\hline Choukan et al., 2006) & 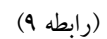 \\
\hline
\end{tabular}

\section{نتايج و بحث}

نتايج تجزيه واريـانس مركـب بـراى صـفات مـورد بررسى نشان داد كه اثر سال براى صـفات ارتفـاع بوتـه، طول خوشه، قطر سـاقه، وزن خوشـه، وزن هـزار دانسه و عملكــرد دانسه در سـطح احتمـال يـكك درصــد و بــراى عملكرد علوفه و عملكرد بيولوزيـك در سـطح احتمـال

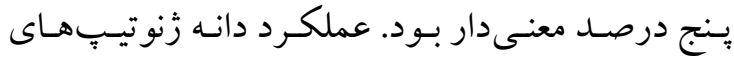
سـور گوم تحـت تــأثير عو امـل ناشسى از اثـر سـال قـرار كرفتنـد. معنى دار بـودن اثر سـال نشـان دهنـده تفــاوت شـرايط محيطى طـى دو سـال آزمـايش اسـت. نتـايج مقايسه ميانگين ها نشان داد كه عملكرد دانه در سال دوم بيشـتر از سـال اول بــود (جـــول (). نتــايج حاصـل از سال اول و دوم آزمايش نشـان دهنـده تفـاوت معنى دار بين تيمارهاى آبيـارى بـراى كليـه صـفات، بـه جـز قطر ساقه بود. نتايج مقايسه ميانكين ها نشـان داد كـه بيشـترين

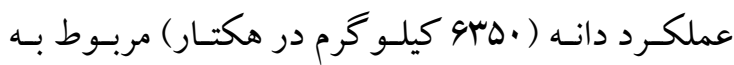
تيمار بدون تسنش (IR $)$ و كمتـرين آن مربسوط بـه تسنش

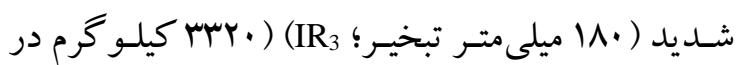

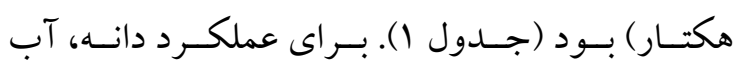

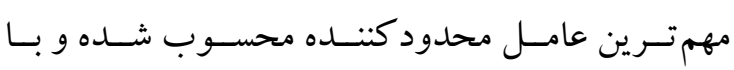
كـاهش ميـزان آب، عملكـــد دانسه بـهــور معنسى دارى 


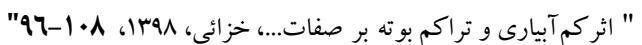

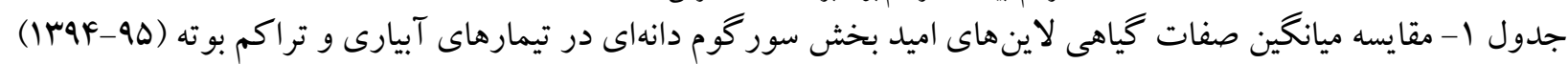

Table 1. Mean of comparison of plant characteristics of promising grain sorghum lines in irrigation and plant density treatments (2015 and 2016)

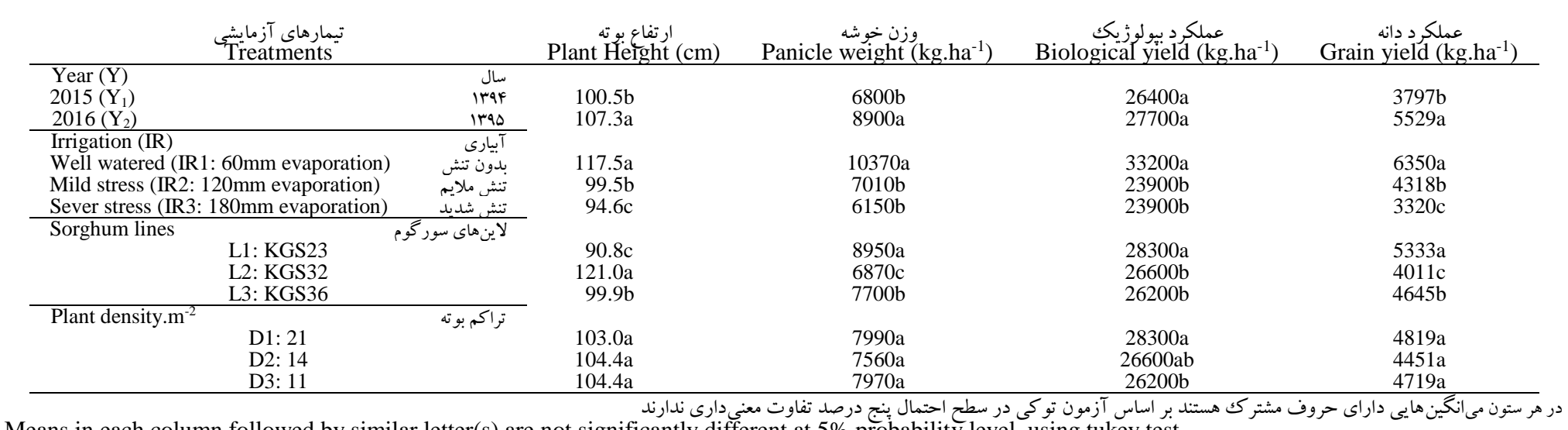

Means in each column followed by similar letter(s) are not significantly different at 5\% probability level, using tukey test

جدول 1- ادامه

Table 1. Continue

\begin{tabular}{|c|c|c|c|c|c|c|c|c|c|}
\hline Treatments & تيمارهاى آزماشي & $\begin{array}{c}\text { ارتفاع بوته } \\
\text { Plant height } \\
\text { (cm) }\end{array}$ & 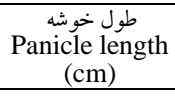 & $\begin{array}{c}\text { قطر ساقه } \\
\text { Stem diameter } \\
(\mathrm{cm})\end{array}$ & 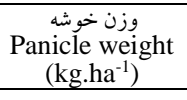 & 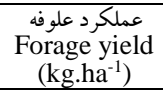 & 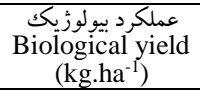 & $\begin{array}{c}\text { وزن هزار دانه } 1000 \text { grain weight } \\
\text { (g) } \\
\end{array}$ & $\begin{array}{c}\text { عملكرد دانه } \\
\text { Grain yield } \\
\left(\mathrm{kg} \cdot \mathrm{ka}^{-1}\right)\end{array}$ \\
\hline Line×Density & لااين ×تراكم بوته & & & & & & & & \\
\hline L1:KGS23×D1 & & $90.4 d$ & $19.5 \mathrm{c}$ & $1.66 \mathrm{c}$ & $9410 \mathrm{a}$ & $17130 \mathrm{~cd}$ & $25990 a-c$ & $22.8 \mathrm{c}$ & $5754 a$ \\
\hline L2:KGS32×D1 & & $119.9 \mathrm{a}$ & $29.2 \mathrm{a}$ & $1.70 \mathrm{bc}$ & $6820 \mathrm{c}$ & $23230 \mathrm{a}$ & $30050 \mathrm{a}$ & $27.4 \mathrm{~b}$ & $3981 \mathrm{c}$ \\
\hline L3:KGS36×D1 & & $98.7 \mathrm{bc}$ & $25.2 \mathrm{~b}$ & $2.29 \mathrm{a}$ & $7730 \mathrm{a}-\mathrm{c}$ & $21160 \mathrm{ab}$ & $28900 \mathrm{ab}$ & $29.5 \mathrm{ab}$ & $4723 a-c$ \\
\hline L1:KGS23×D2 & & $89.4 \mathrm{~d}$ & $19.8 \mathrm{c}$ & $1.57 \mathrm{c}$ & $8350 a-c$ & $16270 \mathrm{~d}$ & $24620 \mathrm{bc}$ & $22.8 \mathrm{c}$ & 4856a-c \\
\hline L2:KGS32×D2 & & $122.7 \mathrm{a}$ & $30.1 \mathrm{a}$ & $1.92 \mathrm{~b}$ & $6820 \mathrm{c}$ & $21040 \mathrm{ab}$ & $27870 a-c$ & $28.4 \mathrm{ab}$ & $3978 \mathrm{c}$ \\
\hline L3:KGS36×D2 & & $101.2 \mathrm{~b}$ & $24.7 \mathrm{~b}$ & $2.30 \mathrm{a}$ & $7500 \mathrm{bc}$ & $19970 \mathrm{a}-\mathrm{c}$ & $27480 \mathrm{a}-\mathrm{c}$ & $28.1 \mathrm{ab}$ & $4520 \mathrm{bc}$ \\
\hline L1:KGS23×D3 & & $92.6 \mathrm{~cd}$ & $20.1 \mathrm{c}$ & $1.61 \mathrm{c}$ & $9090 \mathrm{ab}$ & 14940d & $24030 \mathrm{c}$ & $23.0 \mathrm{c}$ & $5389 \mathrm{ab}$ \\
\hline L2:KGS32×D3 & & $120.6 \mathrm{a}$ & $28.5 \mathrm{a}$ & $1.81 \mathrm{bc}$ & $6960 \mathrm{c}$ & $20090 a-c$ & $27060 \mathrm{a}-\mathrm{c}$ & $28.2 \mathrm{ab}$ & $4075 \mathrm{c}$ \\
\hline L3:KGS36×D3 & & $99.8 \mathrm{~b}$ & $24.5 \mathrm{~b}$ & $2.40 \mathrm{a}$ & $7870 a-c$ & $19790 \mathrm{bc}$ & $27650 a-c$ & $30.1 \mathrm{a}$ & $4694 a-c$ \\
\hline Irrigation $\times$ Line & لاين ×آبيارى & & & & & & & & \\
\hline IR1×L1:KGS23 & & $103.7 \mathrm{~d}$ & $21.6 \mathrm{fg}$ & $1.53 \mathrm{c}$ & $11790 \mathrm{a}$ & $19450 \mathrm{~b}$ & $31230 \mathrm{a}$ & $24.1 \mathrm{~d}$ & $7113 \mathrm{a}$ \\
\hline IR1×L2:KGS32 & & $133.2 \mathrm{a}$ & $32.5 \mathrm{a}$ & $1.75 b c$ & $8970 \mathrm{bc}$ & $24650 \mathrm{a}$ & $33630 \mathrm{a}$ & $29.7 \mathrm{ab}$ & $5586 \mathrm{bc}$ \\
\hline IR1×L3:KGS36 & & $115.8 \mathrm{bc}$ & $27.3 \mathrm{bc}$ & $2.37 \mathrm{a}$ & $10360 \mathrm{ab}$ & $24390 \mathrm{a}$ & $34760 \mathrm{a}$ & $30.8 \mathrm{a}$ & $6352 \mathrm{ab}$ \\
\hline IR $2 \times L 1: K G S 23$ & & $85.4 \mathrm{f}$ & $19.5 \mathrm{gh}$ & $1.62 \mathrm{bc}$ & $8100 \mathrm{~cd}$ & $14030 \mathrm{~d}$ & $22130 \mathrm{bc}$ & $23.4 \mathrm{de}$ & $5053 c$ \\
\hline IR $2 \times L 2: K G S 32$ & & $119.2 \mathrm{~b}$ & $28.9 \mathrm{~b}$ & $1.84 \mathrm{~b}$ & $6010 \mathrm{e}$ & $19490 \mathrm{~b}$ & $25510 \mathrm{bc}$ & $27.9 \mathrm{bc}$ & $3405 \mathrm{de}$ \\
\hline IR $2 \times$ L3:KGS36 & & $94.0 \mathrm{e}$ & $24.3 \mathrm{de}$ & $2.37 \mathrm{a}$ & 6900de & $17560 \mathrm{bc}$ & $24460 \mathrm{bc}$ & $29.2 \mathrm{ab}$ & $4498 \mathrm{~cd}$ \\
\hline IR3 3 L1:KGS23 & & $83.3 \mathrm{f}$ & $18.3 \mathrm{~h}$ & $1.68 \mathrm{bc}$ & $6970 \mathrm{de}$ & $14860 \mathrm{~cd}$ & $21270 \mathrm{c}$ & $21.1 \mathrm{e}$ & $3832 \mathrm{de}$ \\
\hline IR3 3 L2:KGS32 & & $110.7 \mathrm{~cd}$ & $26.3 \mathrm{~cd}$ & $1.84 \mathrm{~b}$ & $5620 \mathrm{e}$ & $20220 \mathrm{~b}$ & $25840 \mathrm{~b}$ & $26.4 \mathrm{c}$ & $3042 \mathrm{e}$ \\
\hline IR3 3 L3:KGS36 & & $89.8 \mathrm{ef}$ & $22.8 \mathrm{ef}$ & $2.26 \mathrm{a}$ & $5850 \mathrm{e}$ & $18970 \mathrm{~b}$ & $24810 \mathrm{bc}$ & $27.8 \mathrm{bc}$ & $3087 \mathrm{e}$ \\
\hline
\end{tabular}

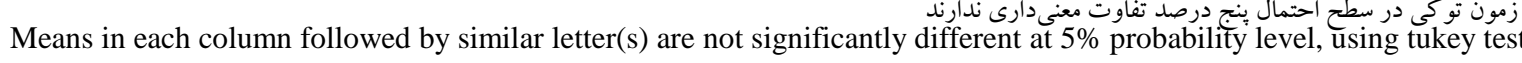




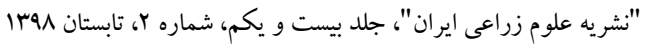

جدول ا- ادامه

Table 1. Continue

\begin{tabular}{|c|c|c|c|c|c|c|c|c|c|}
\hline Treatments & تيمارهاى آزمايشى & $\begin{array}{c}\text { ارتفاع بوته } \\
\text { Plant height } \\
\text { (cm) }\end{array}$ & $\begin{array}{c}\text { طول خوشهicle length } \\
\text { (cm) }\end{array}$ & $\begin{array}{c}\text { قطر ساقه } \\
\text { Stem diameter } \\
(\mathrm{cm})\end{array}$ & $\begin{array}{c}\text { وزن خوشه } \\
\text { Panicle weight } \\
\left(\mathrm{kg}^{\prime} \mathrm{ha}^{-1}\right)\end{array}$ & 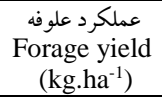 & $\begin{array}{c}\text { عملكرد بيولوزيكيك } \\
\text { Biological yield } \\
\left.\text { (kg.ha }{ }^{-1}\right)\end{array}$ & $\begin{array}{l}\text { وزن هزار دانه } 1000 \text { grain weight } \\
\text { (g) }\end{array}$ & $\begin{array}{c}\text { عملكرد دانه } \\
\text { Grain yield } \\
\left(\mathrm{kg}^{2} \mathrm{ha}^{-1}\right) \\
\end{array}$ \\
\hline Irrigation $\times$ Density $\times$ Line & لاين ×تراكم ×آبيارى & & & & & & & & \\
\hline $\mathrm{IR} 1 \times \mathrm{D} 1 \times \mathrm{L} 1: \mathrm{KGS} 23$ & & $104.8 \mathrm{~d}-\mathrm{i}$ & $21.5 \mathrm{gh}$ & $1.42 \mathrm{~d}$ & $12160 \mathrm{a}$ & 21480a-g & 33630ab & $25.0 \mathrm{e}-\mathrm{h}$ & $7513 a$ \\
\hline IR $1 \times D 1 \times L 2: K G S 32$ & & $133.6 \mathrm{a}$ & $32.5 \mathrm{a}$ & $1.73 \mathrm{~cd}$ & $8590 \mathrm{a}-\mathrm{h}$ & $27190 a^{\circ}$ & $35790 \mathrm{a}$ & $29.0 \mathrm{a}-\mathrm{e}$ & 5578a-e \\
\hline IR $1 \times D 1 \times L 3: K G S 36$ & & $116.3 \mathrm{c}-\mathrm{f}$ & $27.1 \mathrm{~cd}$ & $2.22 \mathrm{ab}$ & 10730a-d & $25020 \mathrm{ab}$ & $35750 \mathrm{a}$ & $33.5 \mathrm{a}$ & $6597 \mathrm{a}-\mathrm{c}$ \\
\hline $\mathrm{IR} 1 \times \mathrm{D} 2 \times \mathrm{L} 1: \mathrm{KGS} 23$ & & 103.6e-i & $21.9 \mathrm{gh}$ & $1.74 \mathrm{~cd}$ & $11380 \mathrm{ab}$ & $18130 \mathrm{~b}-\mathrm{i}$ & 29490a-f & $22.3 \mathrm{gh}$ & $6547 \mathrm{a}-\mathrm{c}$ \\
\hline $\mathrm{IR} 1 \times \mathrm{D} 2 \times \mathrm{L} 2: \mathrm{KGS} 32$ & & $132.4 \mathrm{ab}$ & $33.3 \mathrm{a}$ & $1.71 \mathrm{~cd}$ & $8820 \mathrm{a}-\mathrm{h}$ & 23560a-d & 32390a-d & $30.0 \mathrm{a}-\mathrm{d}$ & 5593a-e \\
\hline $\mathrm{IR} 1 \times \mathrm{D} 2 \times \mathrm{L} 3: \mathrm{KGS} 36$ & & $117.8 \mathrm{bc}-\mathrm{e}$ & $27.9 \mathrm{bc}$ & $2.30 \mathrm{ab}$ & $9430 \mathrm{a}-\mathrm{f}$ & $23610 a-d$ & $33050 \mathrm{a}-\mathrm{c}$ & $26.9 \mathrm{~b}-\mathrm{g}$ & $5725 a-d$ \\
\hline IR1×D3×L1:KGS23 & & $102.6 f-j$ & $21.3 \mathrm{gh}$ & $1.71 \mathrm{~cd}$ & 11830ab & $18750 b-i$ & 30570a-e & $25.0 \mathrm{e}-\mathrm{h}$ & $7281 \mathrm{a}$ \\
\hline $\mathrm{IR} 1 \times \mathrm{D} 3 \times \mathrm{L} 2: \mathrm{KGS} 32$ & & $133.4 \mathrm{a}$ & $31.8 \mathrm{ab}$ & $1.69 \mathrm{~cd}$ & 9510a-e & 23190a-e & $32710 a-d$ & $30.0 \mathrm{a}-\mathrm{d}$ & 5588a-e \\
\hline IR $1 \times \mathrm{D} 3 \times \mathrm{L} 3: \mathrm{KGS} 36$ & & $113.4 \mathrm{c}-\mathrm{f}$ & $26.8 \mathrm{~cd}$ & $2.26 \mathrm{ab}$ & 10930a-c & $24550 a-c$ & $35480 \mathrm{a}$ & $31.9 \mathrm{ab}$ & $6733 a b$ \\
\hline IR $2 \times \mathrm{D} 1 \times \mathrm{L} 1: \mathrm{KGS} 23$ & & $84.5 \mathrm{k}$ & $19.3 \mathrm{ij}$ & $1.64 \mathrm{~cd}$ & $9050 \mathrm{a}-\mathrm{g}$ & 14060hi & $23090 \mathrm{e}-\mathrm{g}$ & $22.5 \mathrm{f}-\mathrm{h}$ & 5760a-d \\
\hline IR2×D1×L2:KGS32 & & $120.1 \mathrm{a}-\mathrm{c}$ & $29.8 \mathrm{ab}$ & $1.77 \mathrm{~cd}$ & 6190e-h & 20820a-h & $27020 \mathrm{a}-\mathrm{g}$ & $27.4 b-f$ & 3419d-f \\
\hline IR2×D1×L3:KGS36 & & $93.5 \mathrm{~h}-\mathrm{k}$ & $25.5 \mathrm{~cd}$ & $2.52 \mathrm{a}$ & 7190c-h & 20120a-h & 27330a-g & $29.3 \mathrm{a}-\mathrm{e}$ & $4675 b-f$ \\
\hline IR $2 \times \mathrm{D} 2 \times \mathrm{L} 1: \mathrm{KGS} 23$ & & $84.2 \mathrm{k}$ & $19.0 \mathrm{ij}$ & $1.50 \mathrm{~d}$ & 7080d-h & $16170 \mathrm{e}-\mathrm{i}$ & $23250 \mathrm{e}-\mathrm{g}$ & $25.1 \mathrm{~d}-\mathrm{h}$ & $4263 b-f$ \\
\hline $\mathrm{IR} 2 \times \mathrm{D} 2 \times \mathrm{L} 2: \mathrm{KGS} 32$ & & $119.9 \mathrm{a}-\mathrm{d}$ & $27.5 \mathrm{bc}$ & $1.97 \mathrm{bc}$ & 6040e-h & 20230a-h & $26260 \mathrm{~b}-\mathrm{g}$ & $28.5 \mathrm{~b}-\mathrm{e}$ & $3208 \mathrm{ef}$ \\
\hline
\end{tabular}

Means in each column followed by similar letter(s) are not significantly different at 5\% probability level, using tukey test

جدول 1- ادامه

Table 1. Continue

\begin{tabular}{|c|c|c|c|c|c|c|c|c|c|}
\hline Treatments & ت تمارهاى آزماشي & $\begin{array}{c}\text { ارتفاع بوته } \\
\text { Plant Height } \\
\text { (cm) }\end{array}$ & $\begin{array}{l}\text { طول خوشه } \\
\text { Panicle length } \\
\text { (cm) }\end{array}$ & $\begin{array}{c}\text { قطر ساقه } \\
\text { Stem diameter } \\
(\mathrm{cm})\end{array}$ & $\begin{array}{c}\text { وزن خوشه } \\
\text { Panicle weight } \\
\left(\text { kg.ha- }{ }^{-1}\right)\end{array}$ & $\begin{array}{c}\text { عملكرد علوفه } \\
\text { Forage yield } \\
\left(\mathrm{kg}^{2} \mathrm{ha}^{-1}\right)\end{array}$ & $\begin{array}{c}\text { عملكرد بيولوزيكت } \\
\text { Biological yield } \\
\left(\text { kg.ha }^{-1}\right)\end{array}$ & $\begin{array}{l}\text { وزن هزار دانه } 1000 \text { grain weight } \\
\text { (g) }\end{array}$ & $\begin{array}{c}\text { عملكرد دانه } \\
\text { Grain yield } \\
\left(\mathrm{kg}^{2} \text { ha }^{-1}\right)\end{array}$ \\
\hline Cultivars $\times$ Density $\times$ Irrigation & لاين ×تراكم ×آيارى & & & & & & & & \\
\hline $\mathrm{IR} 2 \times \mathrm{D} 2 \times \mathrm{L} 3: \mathrm{KGS} 36$ & & $93.2 \mathrm{~h}-\mathrm{k}$ & $23.8 \mathrm{ef}$ & $2.23 a-e$ & 7170c-h & $17150 \mathrm{~d}-\mathrm{i}$ & $24330 \mathrm{c}-\mathrm{g}$ & $27.9 \mathrm{~b}-\mathrm{e}$ & $4600 \mathrm{~b}-\mathrm{f}$ \\
\hline $\mathrm{IR} 2 \times \mathrm{D} 3 \times \mathrm{L} 1: \mathrm{KGS} 23$ & & $87.5 \mathrm{jk}$ & $20.0 \mathrm{hi}$ & $1.70 \mathrm{fg}$ & 8180b-h & $11860 \mathrm{i}$ & $20030 \mathrm{~g}$ & $22.7 \mathrm{f}-\mathrm{h}$ & $5138 \mathrm{a}-\mathrm{f}$ \\
\hline IR $2 \times \mathrm{D} 3 \times \mathrm{L} 3: \mathrm{KGS} 36$ & & $95.5 \mathrm{~g}-\mathrm{k}$ & $23.8 \mathrm{ef}$ & $2.48 \mathrm{ab}$ & $6320 \mathrm{e}-\mathrm{h}$ & 15390f-i & $21710 \mathrm{e}-g$ & $30.3 a-c$ & $4218 \mathrm{c}-\mathrm{f}$ \\
\hline IR3 3 D1×L1:KGS23 & & $81.9 \mathrm{k}$ & $17.6 \mathrm{k}$ & $1.72 \mathrm{e}-\mathrm{g}$ & 7040d-h & $15860 \mathrm{f}-\mathrm{i}$ & $21230 \mathrm{fg}$ & $21.0 \mathrm{~h}$ & 3990def \\
\hline IR3×D1×L2:KGS32 & & $105.9 \mathrm{c}-\mathrm{h}$ & $25.3 \mathrm{de}$ & $1.67 \mathrm{fg}$ & $5690 \mathrm{f}-\mathrm{h}$ & 21670a-f & $27350 a-g$ & $25.9 \mathrm{c}-\mathrm{h}$ & $2944 f$ \\
\hline IR3 $\times$ D $1 \times$ L3:KGS36 & & $86.3 \mathrm{k}$ & $23.1 \mathrm{fg}$ & $2.25 \mathrm{a}-\mathrm{d}$ & $5270 \mathrm{~h}$ & $18340 \mathrm{~b}-\mathrm{i}$ & $23620 \mathrm{~d}-\mathrm{g}$ & $25.8 \mathrm{c}-\mathrm{h}$ & $2896 \mathrm{f}$ \\
\hline IR3×D2×L1:KGS23 & & $80.4 \mathrm{k}$ & $18.4 \mathrm{jk}$ & $1.70 \mathrm{fg}$ & 6600e-h & $14510 \mathrm{~g}-\mathrm{i}$ & $21110 \mathrm{fg}$ & $21.0 \mathrm{~h}$ & $3757 \mathrm{~d}-\mathrm{f}$ \\
\hline IR3×D2×L3:KGS36 & & $92.5 \mathrm{~h}-\mathrm{k}$ & $22.3 \mathrm{gh}$ & $2.13 \mathrm{a}-\mathrm{f}$ & $5900 \mathrm{e}-\mathrm{h}$ & 19160b-h & $25050 \mathrm{~b}-\mathrm{g}$ & $29.4 a-e$ & $3235 \mathrm{ef}$ \\
\hline IR3×D3×L1:KGS23 & & $87.8 \mathrm{jk}$ & $18.9 \mathrm{ij}$ & $1.63 \mathrm{fg}$ & 7270c-h & $14220 \mathrm{hi}$ & $21480 \mathrm{e}-\mathrm{g}$ & $21.2 \mathrm{~h}$ & $3750 \mathrm{def}$ \\
\hline IR3×D3×L2:KGS32 & & $110.6 \mathrm{c}-\mathrm{g}$ & $24.4 \mathrm{ef}$ & $1.83 \mathrm{c}-\mathrm{g}$ & $5560 \mathrm{gh}$ & 19670b-h & $25220 \mathrm{~b}-\mathrm{g}$ & $26.8 \mathrm{c}-\mathrm{g}$ & $3049 \mathrm{f}$ \\
\hline IR3×D3×L3:KGS36 & & $90.6 \mathrm{ijk}$ & $23.1 \mathrm{fg}$ & $2.38 \mathrm{ab}$ & $6360 \mathrm{e}-\mathrm{h}$ & 19410b-h & $25770 \mathrm{~b}-\mathrm{g}$ & $28.3 \mathrm{~b}-\mathrm{e}$ & $3129 \mathrm{ef}$ \\
\hline
\end{tabular}

Means in each column followed by similar letter(s) are not significantly different at 5\% probability level, using tukey test 
" اثر كم آبيارى و تراكم بوته بر صفات...، خزائى، دوسا، 1 +1-77"

اين نتيجه رسيدند كه تعـداد خوشـه در واحسد سططح در زمان خوشهدهى، تحت تأثير كم آبى قرار كرفتـه و كـم

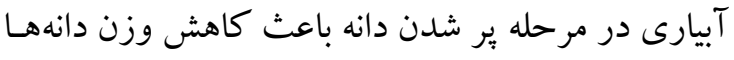

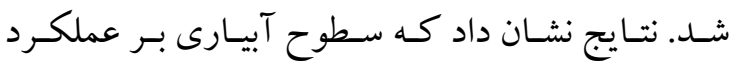

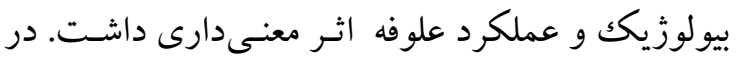
تيمـار بـدون تـنش (IR

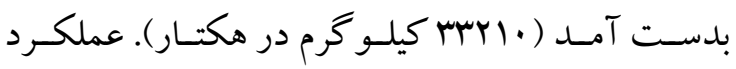

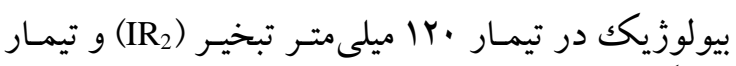

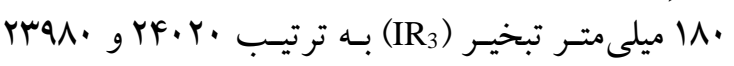
كيلو گرم در هكتار بود (جدول (1).

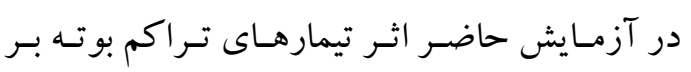

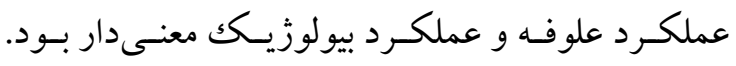
بيشترين عملكرد علوفه و عملكرد بيولوزيكك مربسوط بـ عـهـ

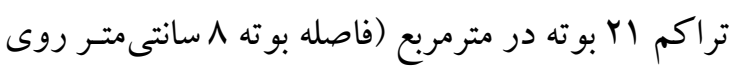

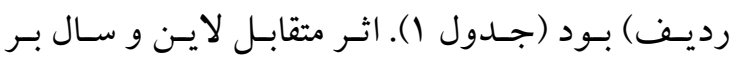
عملكرد علوفه و قطر ساقه معنى دار بود. اثر متقابل لاين و آبيـارى فقـط از لحساظ طـول خوشـهـ معنسى عدار بـود.

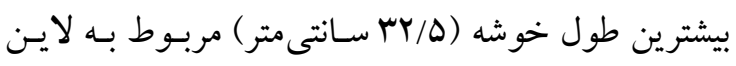
KGS32

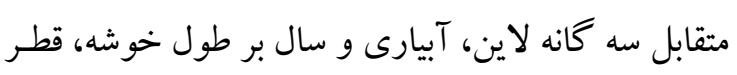

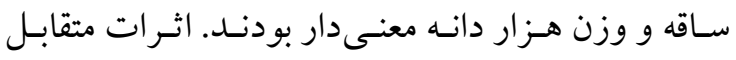

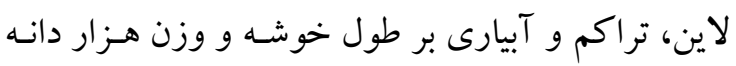

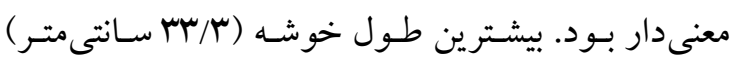
مربوط به تيمـار بـدون تـنش (IR

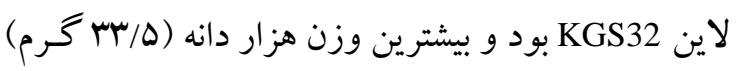

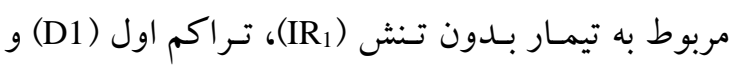

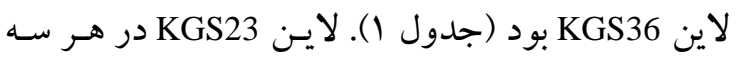

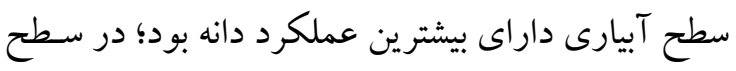

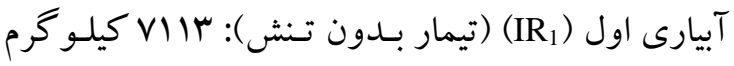

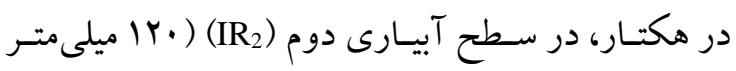

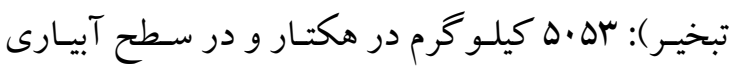

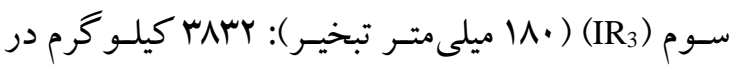

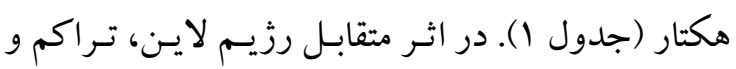

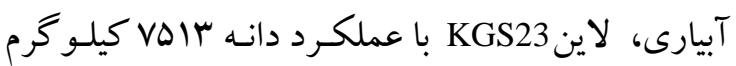

درصد عملكرد در ارزن و ·ـ درصـد در سـور گوم شـد

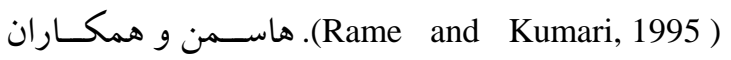
(Hussman et al., 1998)

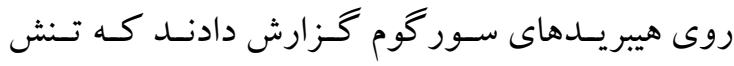

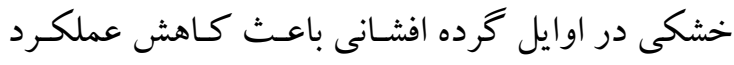
مىشود. ابو الهاشــم و همكـاران (Abulhashem et al., 1998) نيـز

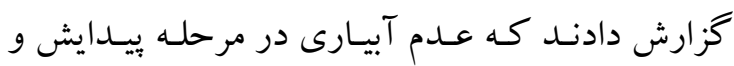

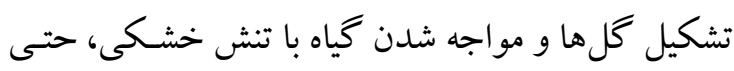

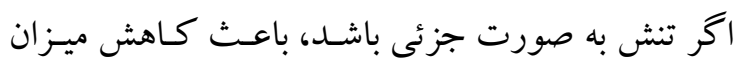

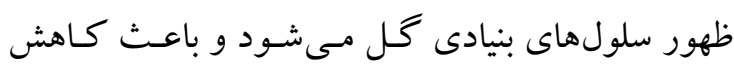

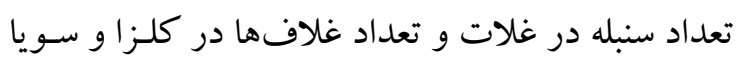

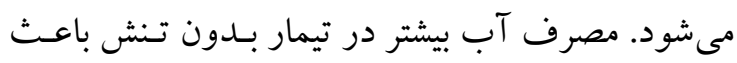

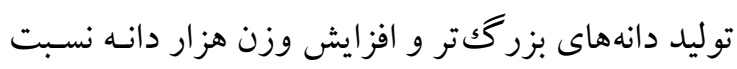

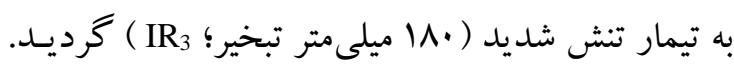

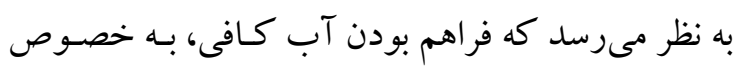

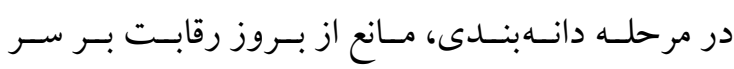
جذب مواد فتوسنتزى بين دانها و اندام رويشى مى مرسود.

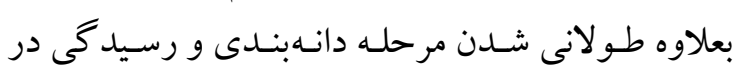

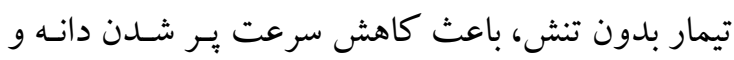

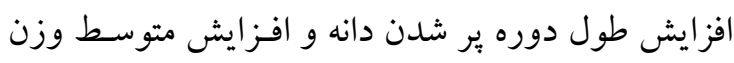

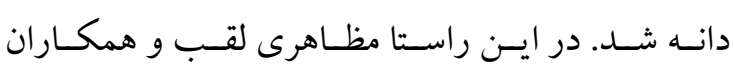
(Mazaheri Laghab et al., 2001)

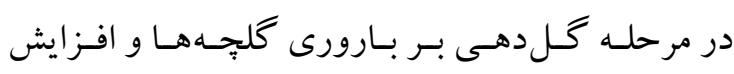

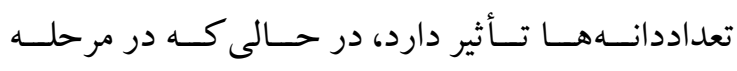

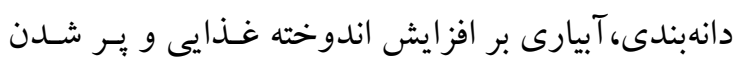

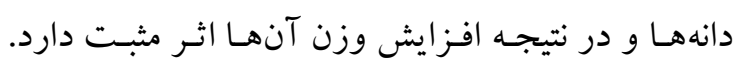

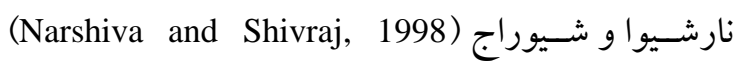

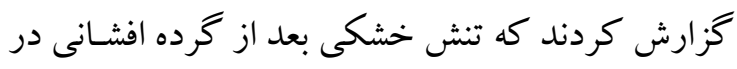

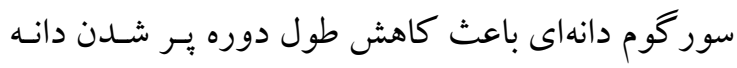

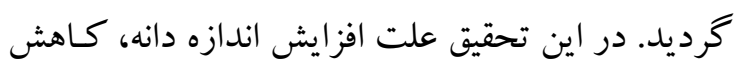
تعداد دانه در خوشه گز ارش شد. اوليوفيايو و همكـاران (Olufayo et al., 1997) شدتهاى تنش خشكى در مراحل مختلف رشد گياه به 
مشــخص مى شــود كــهـ شــاخص TOL در خــزينش

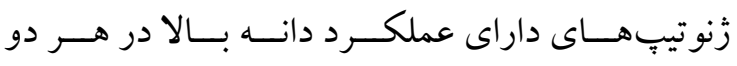

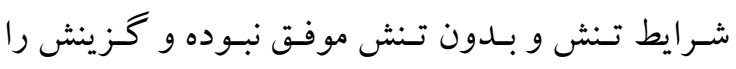

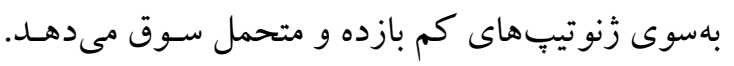

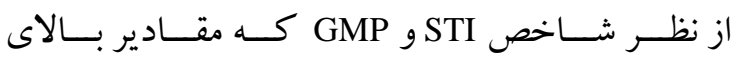

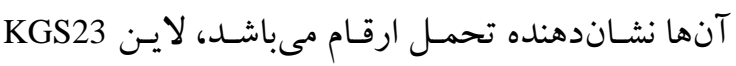

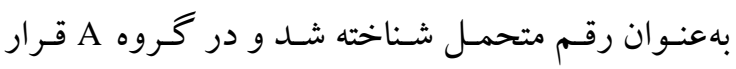

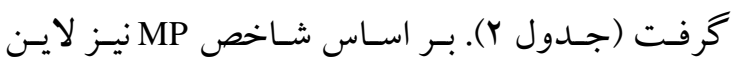

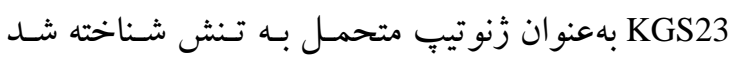

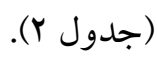

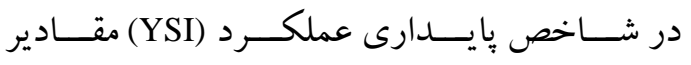
عددى بيشتر از واحد، نشـان دهنـده حساسـيت زنوتيـبـ

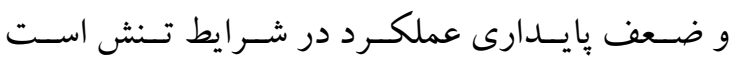

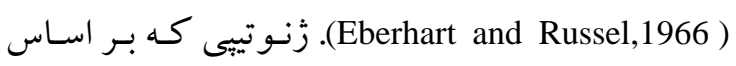

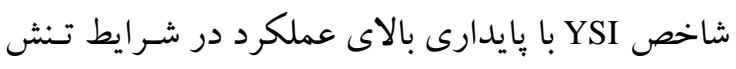

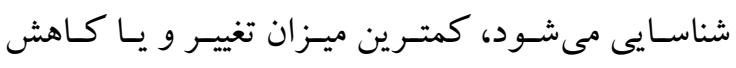

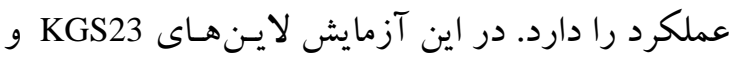

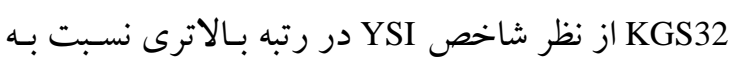

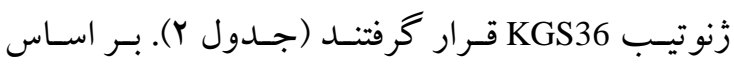

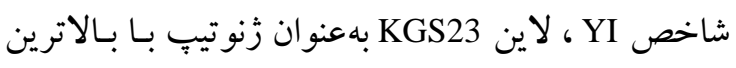

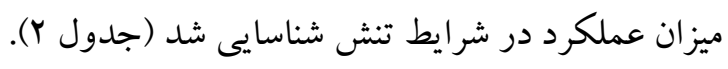

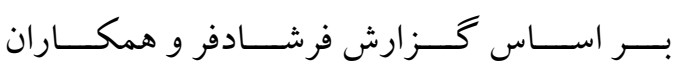

مناسـب ترين شـاخص بـراى (Farshadfar et al., 2001) كزينش ارقام متحمل به تنش، شاخصى است كه داراى

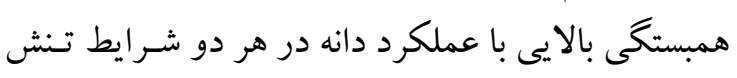

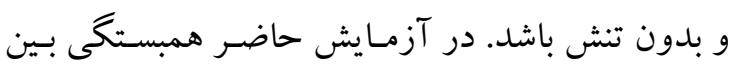

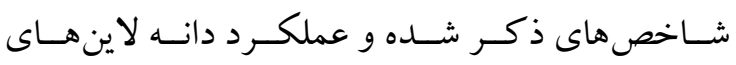

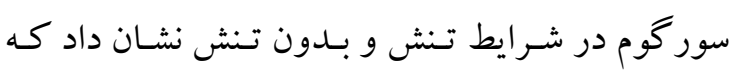

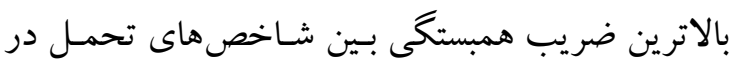

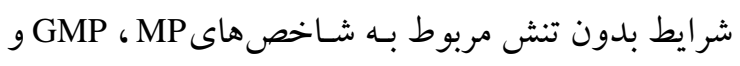

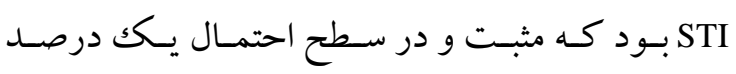

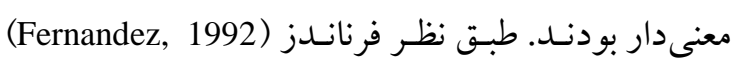

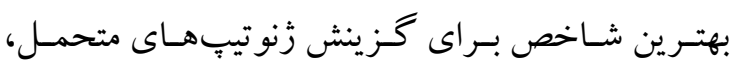

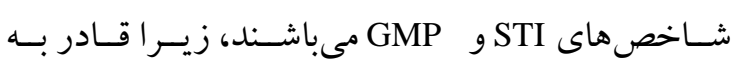

در هكتار در سطح آبيارى اول (IR

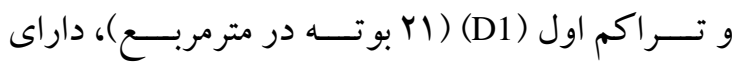
بيشترين عملكرد دانه بود (جدول (1).

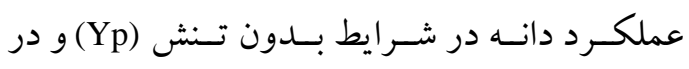

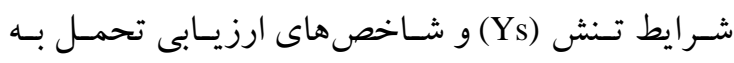

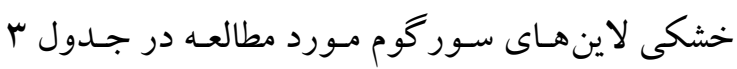

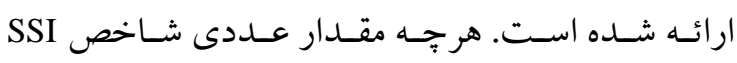

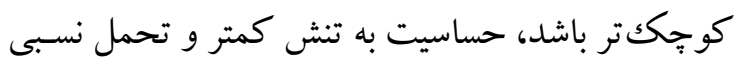

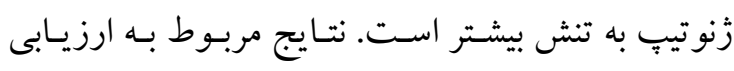

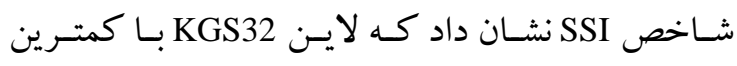

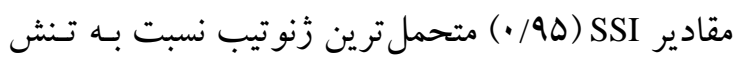

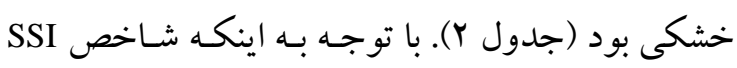

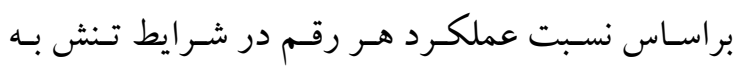

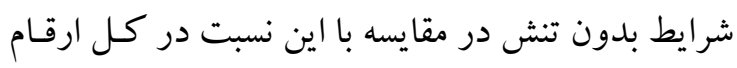

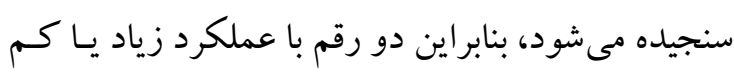
در دو محسيط ممكـن اسـت مقـدار SSI يكسـانى داشـته

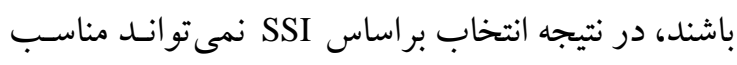

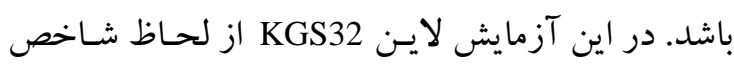

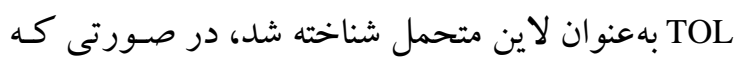
اين لاين در شرايط تنش و بــدون تـنش داراى بـالاترين

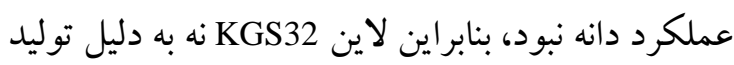

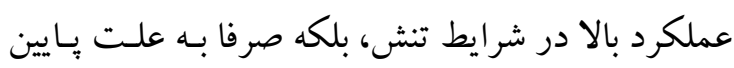

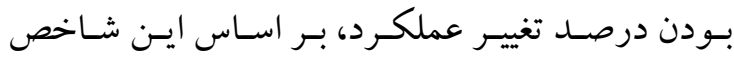

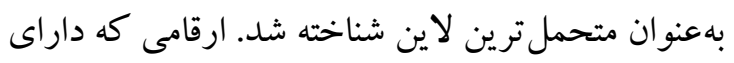

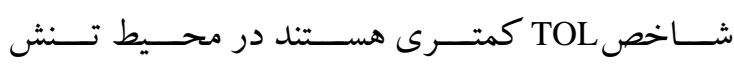

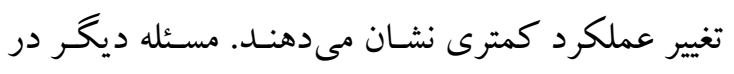

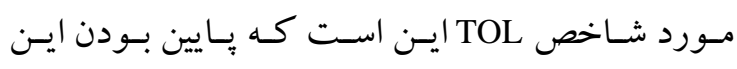
شاخص TOL الزاما به معناى بالا بودن عملكرد رقـم در

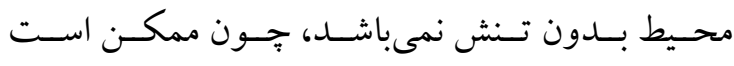

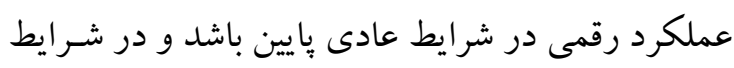

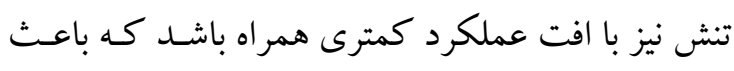

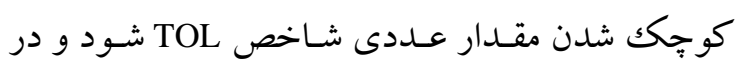

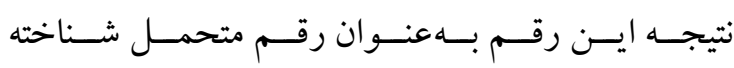
شـود (Moghaddam and Hadizade, 2002)، بنـابراين 
جدول r- بر آورد شاخص هاى تحمل به تنش خشكى لاين هاى اميدبخش سور گوم دانهاى بر اساس عملكرد در شرايط آبيارى كامل (بدون تنش) و كم آبيارى (SI=0.48)

Table 2. Estimation of stress tolerance indices for promising grain sorghum lines based on grain yield under well watered (non-stress) and limited irrigation conditions

$(\mathrm{SI}=0.48)$

\begin{tabular}{|c|c|c|c|c|c|c|c|c|c|c|}
\hline $\begin{array}{l}\text { لاينهاى سوركوم } \\
\text { Sorghum lines }\end{array}$ & $\begin{array}{c}\text { عملكرد در شرايط بدون تنش } \\
\text { Yp (kg.ha-1) }\end{array}$ & $\begin{array}{c}\text { عملكرد در شرايط تنش } \\
\text { Ys (kg.ha-1) }\end{array}$ & $\begin{array}{l}\text { تحمل } \\
\text { TOL }\end{array}$ & $\begin{array}{l}\text { ميانكين حسابى } \\
\text { MP }\end{array}$ & $\begin{array}{l}\text { ميانكين هندسى } \\
\text { GMP }\end{array}$ & $\begin{array}{l}\text { حساسيت به تنش } \\
\text { SSI }\end{array}$ & $\begin{array}{l}\text { تحمل به تنش } \\
\text { STI }\end{array}$ & $\begin{array}{c}\text { شاخص عملكرد } \\
\text { YI }\end{array}$ & $\begin{array}{c}\text { شاخص يايدارى عملكرد } \\
\text { YSI }\end{array}$ & $\begin{array}{c}\text { كاهش عملكرد } \\
\text { R (\%) } \\
\end{array}$ \\
\hline L: KGS23 & 7113 & 3832 & 3281.0 & 5472.9 & 5221.2 & 0.96 & 0.68 & 1.15 & 0.54 & 46 \\
\hline L2: KGS32 & 5586 & 3041 & 2544.3 & 4313.9 & 4122.1 & 0.95 & 0.42 & 0.92 & 0.54 & 46 \\
\hline L3: KGS36 & 6351 & 3086 & 3265.3 & 4719.2 & 4427.8 & 1.07 & 0.49 & 0.93 & 0.49 & 51 \\
\hline Mean ميانكين & 6350 & 3320 & 3030.2 & 4835.4 & 4590.6 & 1.00 & 0.53 & 0.85 & 0.52 & 47.7 \\
\hline
\end{tabular}

جدول ب- ضرايب همبستخى ساده بين شاخص هاى تحمل و عملكرد دانه لاينهاى اميدبخش سور گوم دانهاى در شرايط آبيارى كامل (بدون تنش) و كم آبيارى

Table 3. Correlation coefficients between tolerances indices and grain yield of promising grain sorghum lines under well watered (non-stress) and limited irrigation

\begin{tabular}{|c|c|c|c|c|c|c|c|c|c|c|}
\hline & عملكرد در شرايط بدون تشش & $\begin{array}{c}\text { عملكرد در شرايط تنش } 1 \text { بs } \\
\end{array}$ & $\begin{array}{l}\text { تحمل } \\
\text { TOL }\end{array}$ & $\begin{array}{l}\text { ميانخين حسابى } \\
\text { MP }\end{array}$ & $\begin{array}{c}\text { ميانكين هندسى } \\
\text { GMP } \\
\end{array}$ & $\begin{array}{c}\text { حساسيت به تنش } \\
\text { SSI }\end{array}$ & $\begin{array}{l}\text { تحمل به تنش } \\
\text { STI }\end{array}$ & $\begin{array}{c}\text { شاخص عملكرد } \\
\text { YI }\end{array}$ & $\begin{array}{c}\text { شاخص بايدارى عملكرد } \\
\text { YSI }\end{array}$ & $\begin{array}{c}\text { درصد كاهش عملكرد } \\
\text { R (\%) }\end{array}$ \\
\hline Yp & 1 & & & & & & & & & \\
\hline Ys & 0.89 & 1 & & & & & & & & \\
\hline TOL & 0.88 & 0.56 & 1 & & & & & & & \\
\hline MP & $0.99 * *$ & $0.96^{* *}$ & 0.78 & 1 & & & & & & \\
\hline GMP & $0.97 * *$ & $0.98 * *$ & 0.73 & $.997^{*}$ & 1 & & & & & \\
\hline SSI & 0.08 & -0.39 & 0.55 & -0.10 & -0.18 & 1 & & & & \\
\hline STI & $0.97 * *$ & $0.98^{* *}$ & 0.72 & $1.00^{* *}$ & $1.00^{* * *}$ & -0.18 & 1 & & & \\
\hline YI & 0.88 & $1.00 * *$ & 0.55 & $0.95 * *$ & $0.97 * *$ & -0.40 & $0.98 * *$ & 1 & & \\
\hline YSI & 0.01 & 0.46 & -0.48 & 0.17 & 0.25 & $-1.00 * *$ & 0.26 & 0.47 & 1 & \\
\hline $\mathrm{R}(\%)$ & 0.01 & -0.46 & 0.48 & -0.17 & -0.25 & $1.00 * *$ & -0.26 & -0.47 & $-1.00 * *$ & 1 \\
\hline
\end{tabular}


بيشترين عملكرد دانه مربوط به سطح آبيارى اول (IR) (تيمار بلدون تـنش) بـود. تيمارهـاى تـراكم بوتـه نيـز بـر

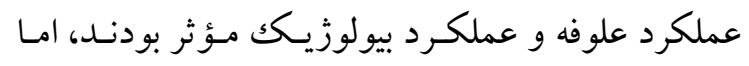
اثرى بر عملكرد دانسه و وزن هـزار دانسه و سـاير صـفات مورد بررسى نداشتتد. با افززايش تـراكم بوتـه، عملكـرد

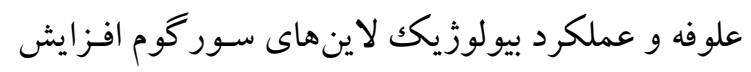
يافت و بيشترين عملكـرد علوفـه و عملكـرد بيولوزيـك

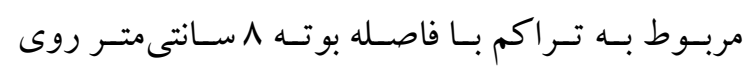
رديف بود. بر اسـاس تيمارهـاى تـراكم و شـاخصهـاى برتر (STI و GMP ، (STI) جهت گزينش لاينهـاى برتر سور گوم متحمل به تنش خشكى، لاين KGS23 بهعنوان لاين متحمل با عملكرد بالا، شناخته شد. بر اساس نتايج

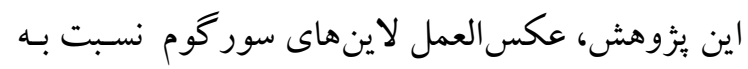
تيمارهاى آبيـارى متفـاوت بـود و لايسن KGS23 از نظر اكثر صفات گياهى مورد ارزيابى در شـرايط كم آبيـارى نسبت به دو لاين ديخر بر ترى معنىدارى داشتت. تعيسين

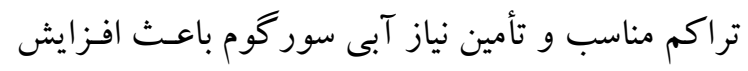
جشمخير عملكرد اين گياه مى مئود.
شناسايى زنوتيٍٍ هايى هستند كه در هر دو محسيط تسنش و بدون تنش داراى عملكرد بالايى هستند. نتايج ارزيابى ضرايب همبستكى عملكرد دانه در شرايط تنش خشكى ونى و بدون تنش با شاخص هاى تحمـل بـه خشكى در ايسن يثزوهش نشـان داد كـه شـاخصهـاى MP و GMP ، بهترين شاخص ها براى شناسـايى لاينهـاى متحمـل بـهـ تنش خشكى سور كوم دانـهاى مسىباشـند. ايسن يافتـه بـا كز ارش شفاز اده و همكاران ( Shafazadeh et al., 2004 مبنى بر اينكه شـاخصهـاى GMP و MPI ، MTI بـه دليـل دارا بودن همبستخى مثبت و معنسى دار بـا عملكر د دانسه

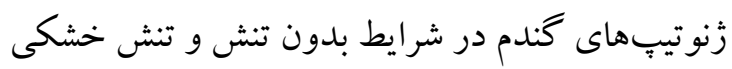
يس از مرحله كل دهى، معيارهاى مناسبى براى شناسايى زَنو تيڤ هاى بر محصول و متحمل به خشكى براى هر دو شر ايط هستند، كاملا همسانى دارد.

$$
\begin{aligned}
& \text { نتيجه تيرى } \\
& \text { بـر اسـاس نتـايج ايسن آزمـايش، بـا كـاهش آبيـارى }
\end{aligned}
$$

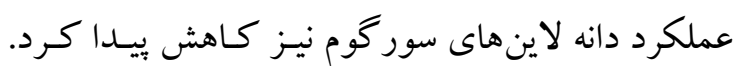

\section{References}

Abulhashem, M., N. Aminmajudar, A. Hamid and M. Hossain. 1998. Drought stress on seed yield attributes growth, cell membrane stability and gas change of synthesized Brassica napus. Indian J. Agron. 180: 129-136.

Amjad Ali, M., A. Abbas, S. Niaz, M. Zulkiffal and S. Ali. 2009. Morpho-physiological criteria for drought tolerance in sorghum (Sorghum bicolor) at seedling and post-anthesis stages. Int. J. Agric. Biol., 11: 674-680.

Bouslama, M. and W. T. Schapaugh. 1984. Stress tolerance in soybean. Part 1: Evaluation of three screening techniques for heat and drought tolerance. Crop Sci. 24: 933-937.

Chatterjee, B. N. and P. K. Das. 1989. Forage Crop Prduction. New Delhi: Oxford \& IBH Publishing Co. Rs 120. ISBN 8120403983.

Choukan, R., T. Taherkhani, M. R. Ghannadha and M. Khodarahmi. 2006. Evaluation of drought tolerance in grain maize inbred lines usineg drought tolerance indices. Iran. J. Agric. Sci. 8(1): 79-89. (In Persian with English abstract).

Done, A. A., R. J. K. Myers and M. A. Foale. 1984. Responses of grain sorghum to varying irrigatiopn frequency inthord irrigatiopn area, I. Growth and development and yield. Aust. J. Agric. Res. 35: 17-29.

Eberhart, S. A. and W. A. Russel. 1966 . Stability paramenters for comparing variaties. Crop Sci. 6: 36-40. 
" اثر كم آبيارى و تراكم بوته بر صفات...، خزائى،

FAO. 2016. FAO data based [online]. Available at, http://faostat.fao.org

Ehdaei, B. 2004. Plant Breeding.Chamran University Press.(In Persian).

Farshadfar, E. A., Zamani, M. R., Matlabi, M. and E. E. Emam-jome. 2001. Selection for drought resistance chickpea lines. Iran. J. Agric. Sci. 32(1): 65-77. (In Persian with English abstract).

Ferrari, E. and J. M. Fernandez. 1986. Genetic variability in sunflower and soybean under drought. 1.Yield relationships. Aust. J. Agric. Res. 37: 573 - 583

Fernandez, G. C. 1992. Effective selection criteria for assessing plant stress tolerance. In: Kuo, C. G.(Ed.), Proceedings of the International Symposium on Adaptation of Vegetables and Other Food Croops in Temperature and Water Stress, Tainan, Taiwan.

Fisher, R . A. and R. Maurer. 1978 . Drought resistance in spring wheat cultivars . Part 1: Grain yield responses. Aust. J. Agric. Res. 29: 897-917.

Gamase, B. P., M. R. Dhawase and B. M. Patil. 1986. Response of high yielding varieties of sorghum under varying levels of Fertility and plant density. PKV. Res. J. 10: 110-114.

Gavazzi, P., F. Rizza, M. Palumbo, R. G. Campaline, G. L. Ricciardi and B. Borghi. 1997. Evaluation of field and laboratory of drought and heat stress in winter cereals. Can. J. Plant Sci. 77: 523-531.

Hussman, B., A. Obilana, A. Blum, P. Ayiecho and W. Schipperack. 1998. Hybrid performance of sorghum and its relationship to morphological and physiological traits under variable drought stress. Plant Breed. 117: 223-229.

Hegde, B. R., J., Maford, D. B. Wilson and K. K. Krogman. 1976. Effectes of row spacing and population density on grain sorghum production in southern Alberta. Can. J. Plant Sci. 56: 31-37.

Heiniger, R. W., R. L. Vanderlip and K. D. Kofoid. 1993. Caryopsis weight patterns within the sorghum panicle. Crop Sci. 33: 543-549.

Hum, D. and J. Kebda. 1981. Response to plant hybrids date and population densing by early- maturing sorghum in Ontario. Can. J. Plant Sci. 61: 265-273.

Jalali, A. H. and M. J. Bahrani. 2001. Quantitative and qualitative characteristics of grain yield of sorghum affected by nitrogen and plant density. J. Agric. Sci. Technol. 5(3): 117 - 125 (In Persian).

Joaquin sanabria, R. J., F. Stone and D. L. Weeks. 1995. Stomatal responseto high evaporative elemad in Irrigated grain sorghum in narrow and wide now spacings. Indian. J. Agron. 87: 1010-1017.

Mazaheri Laghab, H., F. Nouri, H. Zarehabianeh and H. Vafaei. 2001. The effect of terminal irrigation on the important traits of three varieties of sunflower under rainfed conditions.

Agric. Res. (In Persian with English abstract).

Moghaddam, A. and M. H. Hadizade. 2002. Response of maize (Zea mays L.) hybrids and their parental lines to drought using different stress tolerance indices. Seed Plant J. Agric. Res. 18(3): 255-272. (In Persian with English abstract). 


$$
\text { "نشريه علوم زراعى ايران"، جلد بيست و يكم، شماره ب، تابستان ^وبا }
$$

Narshiva Rao, C. L. and A. Shivraj. 1998. Effect of water stress on grain growth of glossy and non glossy varieties of grain sorghum. Indian J. Agric. Sci. 58: 770-773.

Olufayo, A., P. Ruelle, C. Buldy and A. Aidaou, 1997. Biomass of sorghum under variable water regime. Biomass Bioenergy. 12: 383-387.

Onken, A. B., C. W. Wendet , W. A. Payane and M. C. Drew. 1992. Soil phosphorus avaliability and pearl millet water use efficiency. Crop Sci: 32: 1010-1015.

Rame, R. and S. Kumari. 1995. Influence of variable amounts of irrigation water and nitrogen fertilzer on growth, yield and water use of grain sorghum. Aust. J. Agric. Res. 47: 151-161.

Rosolem, C. G., S. M. Kato, J. R. Nachado and S. J. Bicudo. 1993. Nirtogen redistribution to sorghum grain as effected by plant competition. Plant Soil. 155: 199-202.

Rosielle, A. A. and J. Hamblin. 1981. Theoretical aspects of selection fir yield in stress and non stress environment. Crop Sci. 21: 943-946.

Schaffert, N., K. Mattes and A. O. Effenberg. 2011. An investigation of online acoustic information for elite rowers in on-water training conditions. J. Hum. Sport Exer., 6(2): 392-405.

Shafazadeh, M. K., A. Yazdansepas, A. Amini and M. R. Ghannadha. 2004. Study of terminal drought tolerance in promising winter and facultative wheat genotypes using stress susceptibility and tolerance indices. Seed Plant J. 20 (1): 57-71. (In Persian with English abstract).

Wade, L. J. and A. C. Douglass. 1990. Effect of plant density on grain yield and yield stability of sorghum hybrids differing in maturity. Indian. J. Agron. 30: 257-264. 


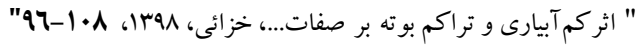

\title{
Effect of deficit irrigation and within row spacing on morphological traits and grain yield of grain sorghum (Sorghum bicolor L. Moench) promising lines
}

\author{
Khazaei, A. ${ }^{1}$
}

\begin{abstract}
Khazaei, A. 2019. Effect of deficit irrigation and within row spacing on morphological traits and grain yield of grain sorghum (Sorghum bicolor L. Moench) promising lines. Iranian Journal of Crop Sciences. 21(2):96-108 (In Persian).
\end{abstract}

To evaluate the effect of deficit irrigation and within row spacing on grain yield and yield components of grain sorghum promising lines, an experiment was conducted as split plot-factorial arrangement in randomized complete block design with three replications in 2015 and 2016 at the research field of Seed and Plant Improvement Institute, Karaj, Iran. Main plots consisted of three irrigation regimes (irrigation applied after 60, 120 and $180 \mathrm{~mm}$ cumulative evaporation from Class A pan) and sub-plots included factorial combination of three levels of within row spacing [8, 12 and $15 \mathrm{~cm}\left(21,14\right.$ and 11 plant. $\mathrm{m}^{-2}$, respectively)] and three promising lines of grain sorghum (KGS23, KGS32, and KGS36). Combined analysis of variance showed that the sorghum prmising lines differed significantly for grain yield. The highest (5333 kg.ha-1) and lowest (4011 kg.ha-1) grain yield obtained from promising lines KGS23 and KGS32, respectively. The results showed that the response of the grain sorghum promising lines to the irrigation regimes was different, and KGS23 was significantly superior in comparison with the other two lines for most of the studied traits. In addition to high grain yield and desirable morphological traits, KGS23 showed adaptibility to deficit irrigation conditions. KGS36 ranked next to KGS23 for grain yield and tolerance to deficit irrigation. The effect of within row spacing on forage yield and biological yield was significant. Decreasing the within row spacing increased the forage and biological yields. Considering the stress tolerance (STI), geometric mean productivity (GMP) and grain yiled, KGS23 promising line which had higher grain yield in all irrigation regimes was identified as tolerant line with high grain yield.

Key words: Deficit irrigation, Grain sorghum, Stress tolerance indices and Forage yield.

Received: December 2018 Accepted: February, 2019

1. Assistant Prof., Seed and Plant Improvement Institute, Agricultural Research, Education and Extension Organization (AREEO), Karaj, Iran (Corresponding author ) (Email: Az42095@yahoo.com) 